Wright State University

CORE Scholar

Mechanical and Materials Engineering Faculty

Publications

Mechanical and Materials Engineering

5-1-1995

\title{
Relationship of the Second Order Nonlinear Optical Coefficient to Bandgap in Inorganic Non-Centrosymmetric Crystals
}

\author{
A. G. Jackson \\ Wright State University - Main Campus, allen.jackson@wright.edu \\ M. Ohmer \\ S. R. Leclair
}

Follow this and additional works at: https://corescholar.libraries.wright.edu/mme

Part of the Materials Science and Engineering Commons, and the Mechanical Engineering Commons

\section{Repository Citation}

Jackson, A. G., Ohmer, M., \& Leclair, S. R. (1995). Relationship of the Second Order Nonlinear Optical Coefficient to Bandgap in Inorganic Non-Centrosymmetric Crystals. .

https://corescholar.libraries.wright.edu/mme/193

This Report is brought to you for free and open access by the Mechanical and Materials Engineering at CORE Scholar. It has been accepted for inclusion in Mechanical and Materials Engineering Faculty Publications by an authorized administrator of CORE Scholar. For more information, please contact library-corescholar@wright.edu. 
WL-TR-95-4098

RELATIONSHIP OF THE SECOND ORDER

NONLINEAR OPTICAL COEFFICIENT TO BANDGAP IN

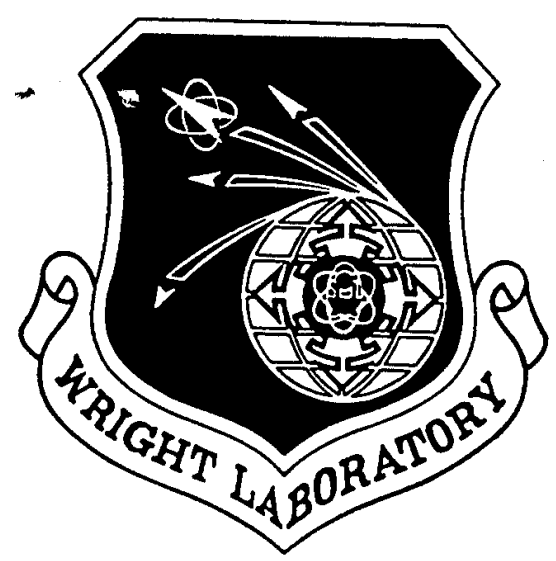

A.G. JACKSON

M. OHMER

S.R. LECLAIR

TMCI

P.O. BOX 340345

BEAVERCREEK OH 45434-0345

MAY 1995

FINAL REPORT FOR 01/01/94-01/01/95

APPROVED FOR PUBLIC RELEASE; DISTRIBUTION IS UNLIMITED.

\section{7}

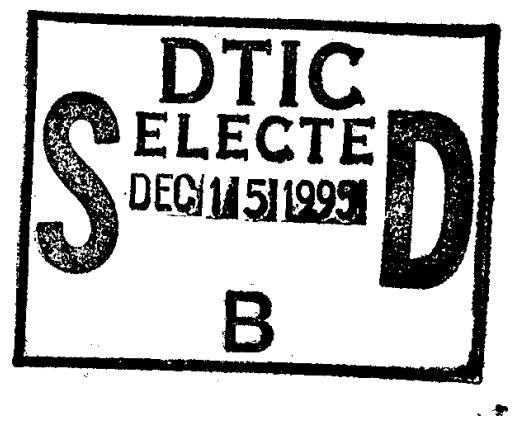

MATERIALS DIRECTORATE

WRIGHT LABORATORY

AIR FORCE MATERIEL COMMAND

WRIGHT PATTERSON AFB OH 45433-7734 


\section{NOTICE}

When Government drawings, specifications, or other data are used for any purpose other than in connection with a definitely Government-related procurement, the United States Government incurs no responsibility or any obligation whatsoever. The fact that the Government may have formulated or in any way supplied the said drawings, specifications, or other data, is not to be regarded by implication, or otherwise in any manner construed, as licensing the holder, or any other person or corporation; or as conveying any rights or permission to manufacture, use, or sell any patented invention that may in any way be related thereto.

This report is releasable to the National Technical Information Service (NTIS). At NTIS, it will be available to the general public, including foreign nations.

This technical report has been reviewed and is approved for publication.
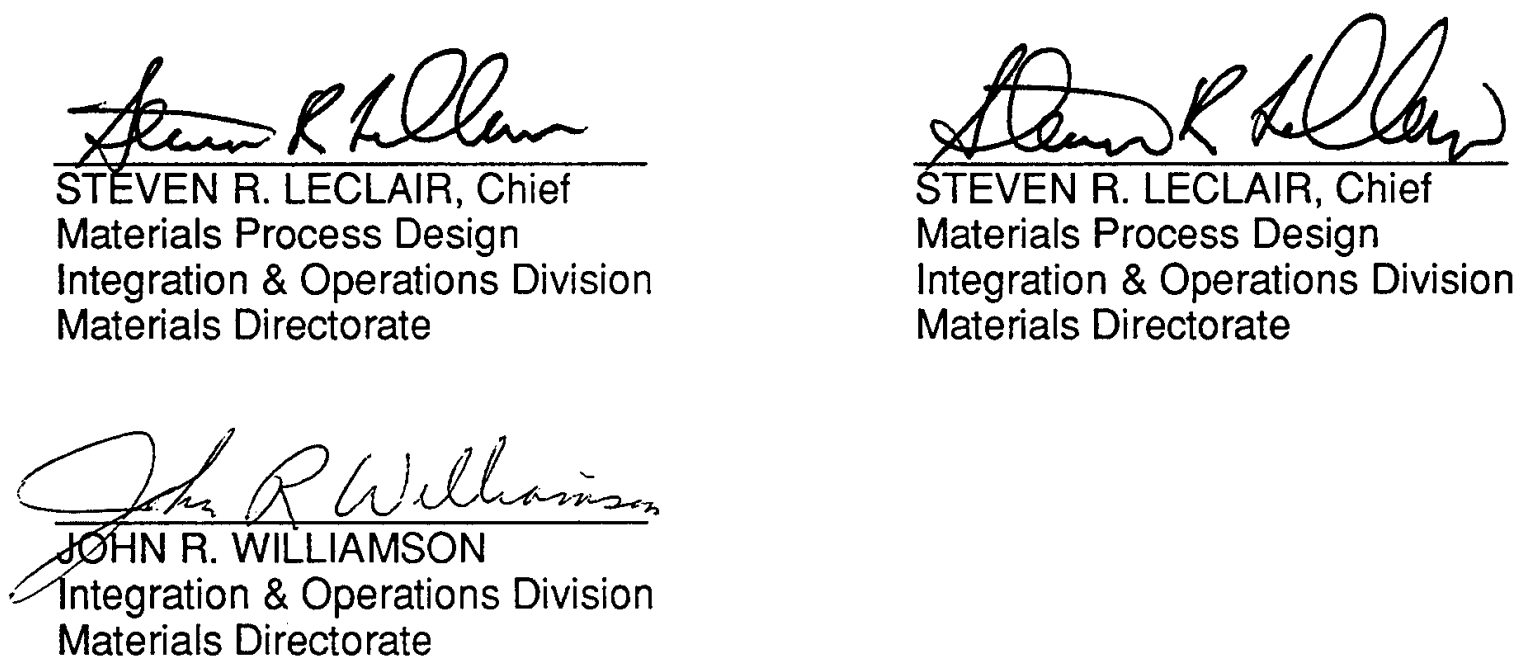

If your address has changed, if you wish to be removed from our mailing list, or if the addressee is no longer employed by your organization please notify WL/MLIM, Wright Patterson AFB, OH 45433 to help maintain a current mailing list.

Copies of this report should not be returned unless return is required by security considerations, contractual obligations, or notice on a specific document. 
Public reporting burden for this collection of information is estumated to average 1 hour per response, including the time for reviewing instructions, searching existing data sources, gathering and maintaining the data needed, and completing and reviewing the collection of information. Send comments regarding this burden estimate or any other aspect of this Dersion of in Davis Highway. Suite 1204, Arlington, VA 22202-4302, and to the Office of Management and Budget, Paperwork Reduction Project (0704-0188), Washington, DC 20503.

\begin{tabular}{|l|c|c|}
\hline 1. AGENCY USE ONLY (Leave blank) & $\begin{array}{c}\text { 2. REPORT DATE } \\
\text { MAY } 1995\end{array}$ & $\begin{array}{r}\text { 3. REPORT TYPE AND DATES COVERED } \\
\text { FINAL }\end{array}$ \\
\hline
\end{tabular}

4. TITLE AND SUBTITLE RELATIONSHIP OF THE SECOND ORDER NONLINEAR OPTICAL COEFEICIENT TO BANDGAP IN IN INORGANIC NON-CENTROSYMMETRIC CRYSTALS

6. AUTHOR(SA.G. JACKSON

M. OHMER

S.R. LECLAIR
5. FUNDING NUMBERS

C F33615-94-D-5801

PE 62102

PR 2418

TA 90

WU 01

7. PERFORMING ORGANIZATION NAME(S) AND ADORESS(ES)

TMCI

8. PERFORMING ORGANIZATION

P.O. BOX 340345

BEAVERCREEK OH $\quad 45434-0345$

REPORT NUMBER

MATERIALS DIRECTORATE

WRIGHT IUABORATORY

AIR FORCE MATERIEL COMMAND

WRIGHT PATTERSON AFB OH 45433-7734

11. SUPPLEMENTARY NOTES

12a. DISTRIBUTION/AVAILABILITY STATEMENT

APPROVED FOR PUBLIC RELEASE; DISTRIBUTION IS

UNLIMITED.

12b. DISTRIBUTION CODE

13. ABSTRACT (Maximum 200 words)

Second order nonlinear optical coefficient data and band gap data collected from the literature have been classified and are organized by plotting their respective values. The two-dimensional plots indicate that both large bandgap and small $X(2)$, and small bandgap - and large $X(2)$ are highly correlated. A corresponding trend is also demonstrated for the figure of merit which is used to rank materials for wavelength conversion efficiency. Results of the analysis are used to estimate the second order nonlinear optical properties and conversion efficiencies of several less-well-known materials. Trend analysis suggests that ordered GalnP 2 would be exceptional as a E-O waveguide material and that the FOM of $\mathrm{AgGaTe}_{2}$, is 3.6 times that of $\mathrm{AgGaSe}_{2}$ and that crystals of $\mathrm{HgGa}_{2} \mathrm{Se}_{4}$ and $\mathrm{Te}_{X} \mathrm{Se}_{(1-\mathrm{x})}$ alloys should be of distinct interest as wavelength conversion materials for infrared applications. The mxaimum attainable $X$ (2) is in the range of $3500-4000 \mathrm{pm} N$ fopr bound electrons. For bandgaps less than one $\mathrm{eV}$, the invrease in $X \quad(2)$ with decreasing bandgap slows considerably.

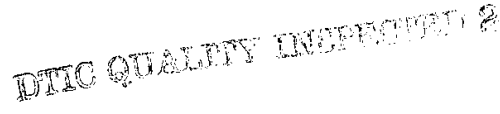

\begin{tabular}{|c|c|c|c|}
\hline \multirow{2}{*}{\multicolumn{3}{|c|}{$\begin{array}{l}\text { 14. SUBJECT TERMS } \\
\text { nonlinear optical properties, crystal, bandgap }\end{array}$}} & \multirow{2}{*}{$\begin{array}{l}\text { 15. NUMBER OF PAGES } \\
\text { 16. PRICE CODE } 30 \\
\end{array}$} \\
\hline & & & \\
\hline $\begin{array}{l}\text { 17. SECURITY CLASSIFICATION } \\
\text { OF REPORT } \\
\text { UNCLASSIFIED }\end{array}$ & $\begin{array}{l}\text { 18. SECURITY CLASSIFICATION } \\
\text { OF THIS PAGE } \\
\text { UNCLASSTFIED }\end{array}$ & $\begin{array}{l}\text { 19. SECURITY CLASSIFICATION } \\
\text { OF ABSTRACT } \\
\text { UNCLASSIFIED }\end{array}$ & $\begin{array}{l}\text { 20. LIMITATION OF ABSTRACT } \\
\text { SAR }\end{array}$ \\
\hline JSN 7540-01-280-5500 & $i$ & & $\begin{array}{l}\text { idard Form } 298 \text { (Rev. 2-89) } \\
\text { ribed by ANSI Std. Z39-18 } \\
102\end{array}$ \\
\hline
\end{tabular}




\section{INTRODUCTION}

The purpose of this paper, is to provide a means of estimating and comparing the wavelength conversion efficiency (figure of merit, FOM) of new nonlinear materials knowing only their bandgap. The approach for the estimates is trend analysis of existing data ${ }^{1-28}$ for the second order nonlinear coefficient, $\chi^{(2)} \mathrm{ijk}$, or $\mathrm{d}_{\mathrm{ij}}=\chi^{(2)} \mathrm{ijk} / 2$, the index of refraction $\mathrm{n}$, and the bandgap $\mathrm{E}$. No underlying physical basis for the result will be presented. The result of this trend analysis, in the form of plots of $\chi^{(2)}$ vs $\mathrm{E}$ and FOM vs $\mathrm{E}$ and the associated fit equations, will be used to estimate $\chi^{(2)}$ and the FOM for wavelength conversion efficiency for some new materials. The accuracy goal agrees within a factor of $2-5$ with the experimental values, which is quite good considering the values range over four to seven orders of magnitude.

In this paper, following the usual conventions, the $\chi^{(2)}$ values are treated as having constant values in the region of high transparency between the bandgap and the onset of multiphonon absorption, and the full $\chi^{(2)}$ values are used, which means the impact of the phase matching angle is ignored. The requirement to phase match often reduces significantly the effective $\chi^{(2)}$ values below those of the full values. The distinction between direct, indirect, or pseudodirect bandgaps is ignored and the minimum room temperature gap is used in all cases.

A number of trends are now well known for semiconductors. Representative examples are: a decreasing thermal conductivity as the bandgap decreases, an increasing mobility as the bandgap decreases, an increasing spin-orbit splitting as the bandgap decreases, a decreasing bandgap as the lattice constant increases, an increasing index of refraction as bandgap decreases, an increasing dielectric constant as bandgap decreases, and increasing non-linear susceptibilities as the linear susceptibilities increase. The last three examples are relevant to the present discussion and will be described in some detail below, followed by some observations related to corresponding ab initio ! calculations.

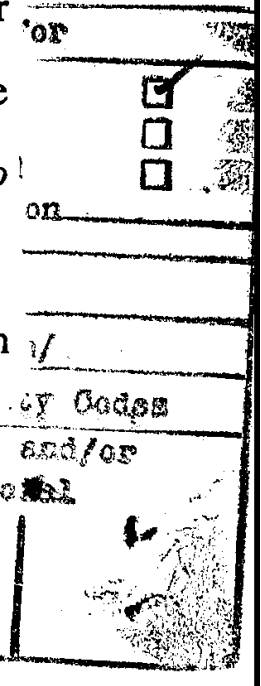


terms of a nonlinear polarization ${ }^{11,28}$. The polarization tensor $\mathbf{P}(\mathbf{E})$ is related to the electric field tensor $\mathbf{E}$ through $\mathrm{Eq}(1)$ or $\mathrm{Eq}(2)$, where, $\chi^{(2)} \mathrm{ij}=2 \mathrm{~d}_{\mathrm{ij}}, \mathrm{K}$ is the dielectric susceptibility, $\chi^{(2)}$ (subscripts are omitted subsequently) and $\chi^{(3)}$ are the nonlinear susceptibility coefficients.

$$
\begin{aligned}
& P(E)=\kappa(E) \cdot E=\kappa_{o} E+\chi^{(2)} \cdot E^{2}+\chi^{(3)} \cdot E^{3}+\cdots \\
& \left.P_{i}=\kappa_{o_{i k}} E_{k}+\chi^{(2)}\right)_{i j} E_{j}^{2}+\cdots
\end{aligned}
$$

In Eq (2), the three dimensional tensor is written in the usual "plane" representation. In the following discussion, the subscripts will be omitted except where helpful for clarity of meaning. All non-centrosymmetric compound semiconductors will have a non-zero $\chi^{(2)}$ and be optically transparent. Generally speaking for infrared applications, all III-V and II-VI compound semiconductors and their pseudo-ternary analogs, the I-III-VI 2 and II-IV-V 2 chalcopyrites with bandgaps of the order of $2 \mathrm{eV}$ or less, have large $\chi^{(2)}$ 's. A number of compounds from these families with $\chi^{(2)}$ 's in the range of $66 \mathrm{pm} / \mathrm{V}$ (i.e., $\mathrm{AgGaSe}_{2}$ ) to the enormous value of $470 \mathrm{pm} / \mathrm{V}$ (i.e., $\mathrm{CdGeAs}_{2}$ ) have received serious consideration for infrared applications.

The usual FOM for wavelength conversion efficiency can be expressed as $\left(\chi^{(2)}\right)^{2} / \mathrm{n}^{3}$, where $\chi$ is the effective $\chi$-value which depends on the specific crystal structure and the direction of the incident optical beam on the crystal and $\mathrm{n}$ is the index of refraction in the transparent region. For the zinc blende or the chalcopyrite semiconductors the appropriate $\chi$ is $\chi_{36}$. It is traditional to compare $\chi^{(2)}$ values only and ignore the issue of beam direction in first order comparisons of the nonlinear optical properties. In this paper trend analysis of $\chi^{(2)}$ vs bandgap and FOM vs bandgap is used to estimate the size of $\chi^{(2)}$ and the FOM for wavelength conversion efficiency for known and unknown materials.

A trend between index of refraction and bandgap was pointed out by $\mathrm{Moss}^{27}$ in 1950. The 
Moss expression for the index of refraction $\mathrm{n}$, where the constant has been slightly modified by Ravindra and Srivastava ${ }^{26}$, is given as $\mathrm{Eq}(3)$, where the energy in this and subsequent equations is in $\mathrm{eV}$ :

$$
n=(108 / E)^{1 / 4}
$$

The data compiled and modeled by Phillips ${ }^{29}$ and VanVechten ${ }^{30}$ presented a corresponding relationship between the dielectric constant $\varepsilon$ or linear susceptibility $\chi^{(1)}$ and energy gap, as pointed out by Soref ${ }^{31}$, as the Moss-like relationships of Eqs (4) and (5).

$$
\varepsilon=(a / E)^{1 / 2}
$$

or

$$
\chi^{(l)}=(b / E)^{1 / 2}
$$

where $\mathrm{a}$ and $\mathrm{b}$ are appropriate constants. Considering that $\mathrm{n}^{2}=\varepsilon, \mathrm{Eq}$ (4) has the same functional form as $\mathrm{Eq}$ (3). The physical basis for $\mathrm{Eq}$ (4), $\mathrm{Eq}$ (5), and by inference $\mathrm{Eq}$ (3), is provided within the framework of the Phillips' bond charge model ${ }^{29,30}$.

Miller $^{32}$ in 1964 noticed that the $\chi^{(2)}$ values available for eleven materials could vary by several orders of magnitude from material to material. He found to his surprise that the $\chi^{(2)}$ is proportional to a product of the three linear susceptibilities. This relationship is now known as Miller's Empirical Rule and the proportionality constant is known as Miller's $\delta_{\mathrm{ij} \text {. Flytzanis }}{ }^{33}$ states that, in a certain sense, this rule was the first hint that nonlinear susceptibilities could be expressed in terms of other macroscopic properties. If the mean value of $\delta_{\mathrm{ij}}$ determined for these 11 materials is used, then all of the $d$ values can be calculated to within a factor of two. The rule can also be written in terms of indices or dielectric constants. For indices the rule can be written ${ }^{31}$ in rationalized mks 
units:

$$
\chi^{(2)}=2\left(8.85 \times 10^{-12}\right)\left(\left(n \omega^{2}-1\right)^{2}\right)\left(n 2{ }^{2}-1\right)\left(\delta_{i j}\right)
$$

where $\chi^{(2)}$ is in $m / V$ and $n_{\omega}$ and $n_{2 \omega}$ are the indices respectively at the frequencies $\omega$ and $2 \omega$. Miller's original constant value for $\delta_{\mathrm{ij}}$ in his units was 0.38 and the specific value for GaAs was 0.24 . Using the presently accepted value of $180 \mathrm{pm} / \mathrm{V}$ for $\chi^{36}$ gives a value for Miller's delta of 0.0246 in rationalized mks units, which yields

$$
\left.\chi^{(2)}=0.436\left(n^{2}-1\right)^{2}\right)\left({ }_{2 \omega}^{2}-1\right)
$$

where the units of $\chi^{(2)}$ are $\mathrm{pm} / \mathrm{V}$.

Subsequently, Flytzanis and Ducuing ${ }^{34}$, in a study of the specific material-to-material variation of $\delta_{\mathrm{ij}}$ within the III-V semiconductor family, found that Miller's delta correlates remarkably well with the dipole moment of the cation-anion bond. Ultimately, using the bond charge model, Levine ${ }^{35}$ provided an approach for calculating the value of $\delta_{\mathrm{ij}}$ for a given material. Levine's value for $\delta_{\mathrm{ij}}$ used in conjunction with Miller's Empirical Rule overestimates the experimental values by $20 \%$ or less for a large number of semiconductors. This modification based on physical insight greatly improved the accuracy of Miller's Empirical Rule. However, it was Miller's Empirical Rule that provided the insight for the establishment of the underlying physical basis for nonlinear optical susceptibility .

Ignoring dispersion, Miller's Empirical Rule, as given by Eq 7, reduces approximately, for large index materials, for $\mathrm{n}^{2}>>1$, to : 


$$
\chi^{(2)}=(0.436) n^{6}\left(\delta_{i j}\right)
$$

Combining Miller's rule, Eq (6), and the Moss relationship, Eq (3), indicates that for $\chi^{(2)} \mathrm{ij}$ increases rapidily as $\mathrm{E}$ decreases, going as $(1 / \mathrm{E})^{3 / 2}$. In the same spirit, the FOM also increases rapidly as $E$ decreases, going as $(1 / \mathrm{E})^{9 / 4}$. Tabulations of $\chi^{(2)}$ values versus transparency range given by Prokhorov ${ }^{37}$, or of the FOM for wavelength conversion versus transparency range given by Shay and Wernick ${ }^{38}$ for representative materials, also suggest the trend that nonlinear properties increase rapidly with decreasing bandgap. The prior successes of empirical property trend analysis have served as the motivation for the FOM trend analysis to follow.

The alternate approach of $a b$ initio calculations of the corresponding quantities, particularly for even-order susceptibilities like $\chi^{(2)}$, is presently not generally feasible. Flytzanis ${ }^{33}$ has reviewed efforts to produce approximate theoretical scaling laws for nonlinear susceptibilities and Levine et al. ${ }^{39}$ and Zhong et al. ${ }^{40}$ have made "near" $a b$ initio calculations of the nonlinear susceptibilities. These two approaches are discussed below.

Flytzanis has shown that odd order nonlinear susceptibilities, like the linear one can be cast in the form of scaling laws, essentially power laws of an effective parameter which turns out to be a measure of the valence electron delocalization and can be expressed in terms of measurable macroscopic quantities. It is found that for three-dimensional systems the odd order susceptibilities scale as:

$$
\chi^{(2 m-1)}=\left(P^{2}\right)\left(1 / E^{(3 m-1)}\right),
$$

where $\mathrm{P}$ is the average transition-dipole-moment matrix element and $\mathrm{m}=0,1,2, \ldots$ For $\chi^{(1)}$ and $\chi^{(3)} \mathrm{Eq}(9)$ gives

$$
\chi^{(l)}=P^{2} / E^{2} \quad(\mathrm{~m}=1)
$$


and

$$
\chi^{(3)}=\left(P^{2}\right)\left(1 / E^{5}\right) . \quad(\mathrm{m}=2)
$$

Note that the ratio of $\chi^{(1)}$ to $\chi^{(3)}$ yields $\chi^{(3)}=\chi^{(1)} / \mathrm{E}^{3}$. Eq (10) may be compared to Eq (5), implying that $\mathrm{P}^{2}$ scales as $\mathrm{E}^{-3 / 2}$, for $\chi^{(1)}$ scaling as $\mathrm{E}^{-1 / 2}$, and that $\chi^{(3)}$ scales as in $\mathrm{Eq}(12)$ below:

$$
\chi^{(3)}=(c)(1 / E)^{65}
$$

where $\mathrm{c}$ is an appropriate constant. These scaling laws were derived in the one-electron approach, ignoring electron correlations via a critical point analysis. These scaling laws might become invalid as the average atomic number of the compound increases to the point that spin-orbit-splitting is a significant portion of the gap. This occurs for very narrow gap materials.

Sheik-Bahae et al. ${ }^{36}$ used a two band model to calculate the scaling of $\chi^{(1)}$ and found that empirically an $\mathrm{E}^{-4}$ dependence is successful in predicting the $\chi^{(3)}$ for a wide variety of semiconductors and insulators over four orders of magnitude. This is a somewhat slower but similar dependence to the $\mathrm{E}^{-6.5}$ dependence given by Eq (12).

It is not possible ${ }^{33}$ to provide a similar approximate theoretical expression for even-order susceptibilities such as $\chi^{(2)}$ because it is sensitive to local properties of the electron density, and integration over the entire Brillouin Zone is required. The physical basis is that the simultaneous requirement for large charge asymmetry and large charge delocalization are competing processes resulting in some cancellation effects. However, the empirical trend for $\chi^{(2)}$ and the approximate theoretical scaling laws for odd order susceptibilities indicate that, generally, susceptibilities are a power law function of the bandgap, increasing rapidly as the bandgap decreases.

The "nearly" ab initio calculations of the nonlinear susceptibilities for some III-V compounds and Se have been reported ${ }^{37,38}$. At present $a b$ initio calculations do not accurately predict the bandgap, tending to produce a value about $1.0 \mathrm{eV}$ too small and a lattice constant 0.100 to 0.200 nanometers too small. Unfortunately, the value of $\chi^{(2)}$ is extremely sensitive to lattice 
constant/bond length and bandgap ${ }^{37}$. These limitations are overcome by adding a constant selfenergy correction to the Hamiltonian to fix the bandgap and using the experimental lattice parameters. This "nearly" ab initio approach then gives good agreement with experimental results for compounds of elements in and above Period IV. However, for elements and compounds in Period V or greater such as $\mathrm{Te}, \mathrm{CdGeAs} 2$, and InSb, this approach does not apply, as once again spin-orbit-splitting has not yet been taken into account. The results for the five materials for which $\chi^{(2)}$ was calculated also shows the general trend that $\chi^{(2)}$ increases rapidly with decreasing bandgap. Fitting the data indicates that $\chi^{(2)}$ increases as $\mathrm{E}^{-3}$ and FOM as $\mathrm{E}^{-6}$.

Flytzanis $^{33}$ points out that the searches for scaling laws and empirical trend analysis for susceptibilities, as for other physical properties, serves many purposes, fundamental as well as practical. They allow the prediction of the properties of new materials by simple inspection, they introduce economy in comparing materials, and they help formulate guidelines for the search for new materials, as well as provide guidance for the development of theory by singling out dominant mechanisms. In the general case, scaling laws and empirical trend analysis are the only tools available for guiding new materials development.

\section{RESULTS AND DISCUSSION}

Using a database compiled from the literature for a number of compounds of interest for nonlinear optical applications, a plot of the second order nonlinear coefficient, $\chi^{(2)}$, versus bandgap has been constructed, and is given in Figure 1. A similar plot of the FOM versus bandgap is given in Figure 2. Where known or observed, uncertainty for these values was noted; otherwise a minimum of $\pm 20 \%$ relative error was assumed, a value most likely too small an error for much of the data in view of the wide variability observed from the literature where some error ranges approach factors of two. In converting from relative to absolute values the value of $\left.\chi^{(2)}\right)_{36}=180$ $\mathrm{pm} / \mathrm{V}$ from reference 14 has been used following general practice. We note that many values 
reported in the literature have been converted using much higher values ranging from 139 to 151 , which give values larger by $50 \%$ to $70 \%$. In Table 1 , Soref's $\chi^{(2)}$ values for IV-IV compounds are used. These are calculated values assuming Miller's rule and using $\delta_{\mathrm{ij}}$ for SiC. This approach, in

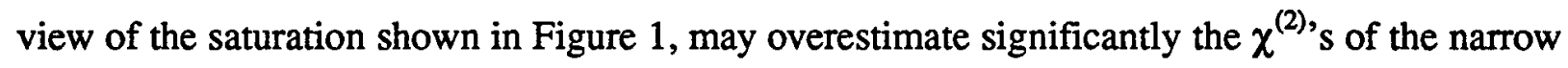
bandgap members of the family such as GeSn.

The general trend of both $\chi^{(2)}$ and FOM is to increase rapidly with decreasing bandgap. In Table 1 are listed the data (and sources) used in the plots. Examination of the curves shows that a single power law expression cannot represent the data well over the total bandgap range. Regression fits were computed which relate $\chi^{(2)}$ to bandgap and FOM to bandgap for a single curve over the full range of $\mathrm{E}$, and two curves. The least squares fits are listed in Table 2. A power law was chosen because it is consistent with the results of the ones discussed in the introduction, although $\chi^{(2)}$ also can be fit reasonably well an $e^{-\mathrm{E}}$ type law $\left(\chi^{(2)}=1134 e^{-1.1 E}\right)$. Clearly, the single curve overestimates large band gap compounds, while underestimating small band gap compounds. For those materials with gaps from about 0.8 to about $3 \mathrm{eV}$, the single curve fit provides an order of magnitude estimate. The two curves provide better estimates for the ranges 0 to about $1 \mathrm{eV}$ and 1 to about $8 \mathrm{eV}$. We note that the Miller's $\delta$ values are rather widespread for this set of compounds, covering a range of about a factor of two, and having an average value of about $0.05 \mathrm{~m}^{2} / \mathrm{C}$.

Calculated values based on Table 2 and actual values are listed in Table 3 for several well known materials. Table 3 indicates that predictions are within a factor of two in the IR for both $\chi^{(2)}$ and FOM, and over the full range all agree approximately within the goal of a factor of 2-5. Further comparisons are presented in Tables 4 and 5. In Table 4, predicted values and actual values for families are compared by calculating ratios for three groupings, using the lowest value of the group as a reference. The results are presented in columns 5 and 6 , and they suggest that the predicted values are close to the actual values where known. Again the accuracy is within a factor of two in the IR. In Table 5 a similar comparison is made for FOM. The results indicate reasonable agreement except for the narrow band, where the predicted value severely underestimates the actual 
value, although the agreement with the relative value is within a factor of two. Also, we note that predicted values of FOM may be in error by factors more than two, because $\chi^{(2)}$ enters FOM as the square. The trend, however, is valid for FOM.

The fits in Table 2 are applied to four promising relatively unknown materials; 1) the recently discovered ordered ternary III-V compound GaInP2, predicted by Wei and $\mathrm{Zunger}^{41}$ for which no nonlinear properties are available, 2) the less well known $\mathrm{AgGaTe}_{2}$ whose nonlinear properties have not been reported and which is a member of the compound family whose two well known

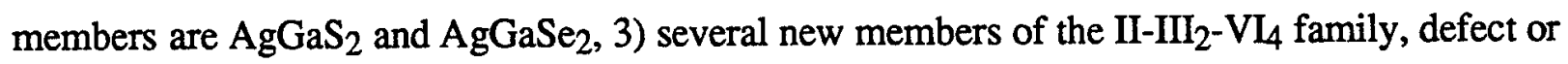
pseudo chalcopyrites, which includes the well known mercury thiogallate, $\mathrm{HgGa}_{2} \mathrm{~S}_{4}$, and 4) TeSe solid solution alloys which have not received the consideration they deserve as very high efficiency materials. These Equations are also applied to three well known materials, $\mathrm{GaAs}, \mathrm{ZnGeP}_{2}$ and $\mathrm{CdGeAs}_{2}$ as baseline comparisons. All of these results are presented in Table 5. As a final discussion, several additonal subtrends based on families of compounds are discussed.

Random ternary alloy III-V semiconductors have received little attention, although their $\chi^{(2)}$ s can be very large, because they are isotropic, and, therefore, do not possess birefringence which is necessary for conventional wavelength conversion processes. However, in the ordered state it would be expected that ternaries like $\mathrm{GaInP}_{2}$ would be birefringent uniaxial crystals. Stenger et al. ${ }^{42}$ have experimentally verified this expectation of adequate birefringence by variable angle spectral ellipsometry measurements for CuPt-like ordering in $\mathrm{GaInP}_{2}$. The estimated $\chi^{(2)}$ from Table 4 for ordered $\mathrm{GaInP}_{2}$ is $130 \mathrm{pm} / \mathrm{V}$, a value large in practical terms. This seems to be a very reasonable value, since it is somewhat less than the trend value for GaAs of $214 \mathrm{pm} / \mathrm{V}$, as would be expected from its slightly larger bandgap, and the trend result for GaAs is in fairly good agreement with the literature ${ }^{19}$ value of $180 \mathrm{pm} / \mathrm{V}$. It would seem that films of ordered $\mathrm{GaInP}_{2}$ would be exceptional waveguide materials.

Some years ago, Bell et al. ${ }^{43}$ investigated the properties of the $\mathrm{AgGaTe}_{2}$ compounds and commented that $\mathrm{AgGaTe}_{2}$ had good mechanical properties and should have a sufficiently large birefringence to be useful for nonlinear optics, although there had not been any studies of this 
aspect of the $\mathrm{AgGaTe} 2$ compounds. Because $\chi^{(2)}$ data for $\mathrm{AgGaTe}_{2}$ is not available from the literature, the estimated value from Table 4 is $233 \mathrm{pm} / \mathrm{V}$. Comparing trend results with literature values for $\mathrm{AgGaS}_{2}$ and $\mathrm{AgGaSe}{ }_{2}$ indicates that, for this family, the trend result overestimates the literature values but does accurately reflect the relative values for these two materials as shown in column VII of Table 4. In Figure (1), the II-VI compounds and their pseudo-ternaries lie generally lower while following the same slope which is consistent with the actual materials dependence of Miller's $\delta$. Relying on the more reliable relative value would give a $\chi^{(2)}$ of $101 \mathrm{pm} / \mathrm{V}$ which exceeds the value for $\mathrm{AgGaSe}_{2}$ by $60 \%$ and more importantly a factor of 3.5 times greater FOM. This material is certainly worth re-exploring.

Radautsan et al. ${ }^{44}$ have surveyed a number of the $\mathrm{II}-\mathrm{III}_{2}-\mathrm{VI}_{4}$ compounds and indicate that their nonlinear properties are interesting. The thiogallates $\mathrm{HgGa}_{2} \mathrm{~S}_{4}, \mathrm{HgGa}_{2} \mathrm{Se}_{4}, \mathrm{HgIn}_{2} \mathrm{Se}_{4}$ are compared using Table 2 and the bandgaps reported by Radautsan et al. The trend result of 36.2 $\mathrm{pm} / \mathrm{V}$ for $\chi^{(2)}$ for $\mathrm{HgGa}_{2} \mathrm{~S}_{4}$ is in reasonable agreement with the literature value ${ }^{11}$ for $\chi^{(2)}$ which ranges from $53.6 \mathrm{pm} / \mathrm{V}$ to $70.4 \mathrm{pm} / \mathrm{V}$. So the trend results listed in Table (3) should be reasonable estimates. For $\mathrm{HgIn}_{2} \mathrm{Se}_{4}$, the estimate for $\chi^{(2)}$ is an impressive $196 \mathrm{pm} / \mathrm{V}$, its FOM is a factor of 15 larger than that of $\mathrm{HgGaS}_{4}$ ! Its range of transparency should be quite large, given its calculated range is from 0.86 microns to much greater than 12 microns, the long-wavelength cut-off of $\mathrm{HgGa}_{2} \mathrm{~S}_{4}$.

Tellurium has the second highest reported $\chi^{(2)}$ for a semiconductor and it is transparent in the infrared. However, in $\mathrm{CO}_{2}$ laser doubling experiments it has been found that two photon absorption and intraband scattering of free carriers limits its application to low power levels. This is a result of its narrow bandgap. This problem could be alleviated by alloying with Se to increase the bandgap. Pure tellurium crystals are quite soft and deformation induced defects also limit its performance ${ }^{45}$. Alloy hardening may adequately improve its mechanical properties. The optical properties of Te crystals alloyed with respectively $2 \%, 2.7 \%$, and $11 \%$ have been reported ${ }^{46,47}$. There is evidence that a solid solution exists for all concentrations ${ }^{46}$ where the lattice constant decreases in a linear fashion as selenium is added to tellurium. The bandgaps in $\mathrm{eV}$ and the 
respective short wavelength cut-offs in microns for the $0 \%, 2.7 \%, 11 \%$, and $100 \%$ cases are respectively $0.358 / 3.46,0.375 / 3.3$, approximately $0.4 / 3.1$, and $1.7 / 0.72$. Alloying provides a method of continuously varying the cut-off from 3.46 to .72 microns. The $\chi^{(2)}$ and the FOM will vary with composition as the bandgap varies as indicated by Eq (4) and (5), but this dependence may be nonlinear, as pointed out by Stuke and $\mathrm{Keller}^{48}$. Thus, a linear interpolation of band gap values from pure Te and pure Se based on composition will yield incorrect results. Using the bandgap composition results of Stuke and Keller, for a $1 \mathrm{eV}$ bandgap/1.24 micron cut-off alloy, the composition $\mathrm{Te}_{286} \mathrm{Se}_{.714}$ is required. Once a bandgap value is estimated, $\chi^{(2)}$ and FOM can be read from the plots; in this case, this compound has a $\chi^{(2)}$ of about $700 \mathrm{pm} / \mathrm{V}$ and FOM of about $3000 \mathrm{pm}^{2} / \mathrm{N}^{2}$.

The intraband scattering mechanism mentioned above which limits the performance of Te will be much less severe in the alloys. As the bandgap is widened the valence band splitting is significantly smaller in comparison, and this scattering mechanism is much less important. In addition, Dubinskaya ${ }^{46}$ reports an approach which may overcome this limitation. Te and, by analogy, these alloys are easily bleached to improve their transparency in the infrared by exposing the crystals to weak visible light sources. The impressively large values for the nonlinear parameters indicate that a serious exploration of this alloy system is warranted.

The power law dependencies for FOM and $\chi^{(2)}$ are summarized in Table 6 and discussed below. Empirically, the FOM depends more strongly on E than $\chi^{(2)}$ does. As a result, reducing the bandgap is significantly more beneficial than the $\chi^{(2)}$ trend alone might indicate. From the fit for $\chi^{(2)}$ in the bandgap range $>1 \mathrm{eV}$, and from the "nearly" $a b$ initio calculation for the $1.4-2.45 \mathrm{eV}$ range, the bandgap dependences are similar, as $\mathrm{m}=2.6$ and 3 , respectively. For the FOM the "nearly" $a b$ initio result and our results give respectively $\mathrm{m}=6$ and $\mathrm{m}=4.1$ (using our large gap value) or $\mathrm{m}=0.9$ using our small gap value, indicating that the field dependence of FOM is overestimated by the calculated results.

For bandgaps $<1 \mathrm{eV}$, the bandgap dependence for both FOM and $\chi^{(2)}$ are strikingly lower as saturation sets in. A comparison of "nearly" ab initio results for the narrow bandgap materials has 
not been made, because the model does not include spin-orbit-splitting and it is useful only for compounds made up of low atomic number atoms ${ }^{49}$. The bond charge model, the approximate $a b$ initio model, and the "nearly" ab initio model fail to predict the saturation observed for FOM and $\chi^{(2)}$, although Miller's rule does, as shown in Figure 1. However, Miller's rule does poorly in the wide bandgap regime, tending to overestimate significantly. At the present time the bandgap dependence over the full range is treated successfully only by trend analysis, which covers materials with a gap of less than one $\mathrm{eV}$.

A more careful look at the trends in Fig. (1) indicates that the data can be grouped in a number of ways to identify sub-trends. Compounds with Group V or VI anions can be grouped as the upper or high bandgap group while oxides and complex structures as the lower or low bandgap group. Using these groupings, there are at least two curves present -- one for narrow bandgap and one for large bandgap. Several compound families show similar slopes when the anion element is considered, for example, $\{\mathrm{ZnS}, \mathrm{ZnSe}, \mathrm{ZnTe}\}$, [CdS, CdSe, CdTe $\},\{\mathrm{GaP}, \mathrm{GaAs}, \mathrm{GaSb}\}$, $\left\{\mathrm{CuGaS}_{2}, \mathrm{CuGaSe}_{2}\right\},\{\mathrm{Se}, \mathrm{Te}\}$ and $\left\{\mathrm{AgGaS}_{2}, \mathrm{AgGaSe}_{2}\right\}$ have similar slopes. The sulfides and the selenides tend to fall below the trend line, for the III-V compounds, in agreement with their smaller Miller's $\delta$ 's. The II-IV-V2 family members, on the other hand, tend to fall above the trend line for the III-V compounds, in agreement with their large Miller's $\delta$ 's. The $\left\{\mathrm{CdGeP}_{2}\right.$, $\left.\mathrm{CdGeAs}_{2}\right\}$ line has a lower slope than the others, as does $\{\mathrm{ZnS}, \mathrm{CdS}, \mathrm{HgS}\}$. The $\{\mathrm{InP}, \operatorname{InAs}$, InSb\} trio does not lie on a line, suggesting that the data may be suspect, probably for the InAs, because the line for InP and InSb has a slope similar to that for similar groupings. The predicted value for In As is about $1650 \mathrm{pm} / \mathrm{V} \pm 500$. If the $\left\{\mathrm{CdGeP}_{2}, \mathrm{CdGeAs}_{2}\right\}$ data is correct, this suggests that the $\chi^{(2)}$ value for $\mathrm{ZnGeAs}_{2}$ should be about $356 \mathrm{pm} / \mathrm{V} \pm 75$ based on the direct bandgap value of about $1.15 \mathrm{eV}$. However, it is anticipated that $\mathrm{ZnGeAs}_{2}$ will not possess an adequate birefringence, because its tetragonal distortion is zero (i.e., $c / a=2.0$ ). 


\section{CONCLUSIONS}

As a means for quickly estimating the value of a material, these curves offer a simple and direct means for classifying nonlinear optical materials. The plots show a strong trend in the data, i.e., $\chi^{(2)}$ increasing rapidly with decreasing bandgap. The FOM depends more strongly on E than $\chi^{(2)}$ does, and, as a result, reducing the bandgap os significantly more beneficial than the $\chi^{(2)}$ trend alone might indicate. The bandgap dependence of the "nearly" $a b$ initio and that of our empirical result for the bandgap near and above one $\mathrm{eV}$ are identical. A saturation of $\chi^{(2)}$ at band gaps below one $\mathrm{eV}$ is observed in our empirical trend, although the various models described fail to predict this behavior, and trend analysis is superior to Miller's rule for large bandgaps. This relationship alone is of value in estimating $\chi^{(2)}$ for a compound based on band gap value. Thus, a noncentrosymmetric compound can be evaluated in broad terms as to its utility as a $\chi^{(2)}$ nonlinear optical material. Trend analysis indicates that films of ordered $\mathrm{GaInP}_{2}$ would be exceptional as $\mathrm{E}$ O waveguide materials, that the $\mathrm{FOM}$ of $\mathrm{AgGaTe}_{2}$ is an impressive factor of 3.5 times greater than that of $\mathrm{AgGaSe} 2$ and crystals of $\mathrm{HgGa}_{2} \mathrm{Se}_{4}$, and that $\mathrm{Te}_{\mathrm{X}} \mathrm{Se}(1-\mathrm{x})$ alloys are of distinct interest, because they are very efficient wavelength conversion materials for infrared application.

\section{ACKNOWLEDGMENT}

AGJ gratefully acknowledges the support provided by AF contract F33615-90-5944 with Wright Laboratory. 


\section{REFERENCES}

1. J. E. Jaffe and A. Zunger, Phys. Rev. B 28, 5822 (1983).

2. J. C. Rife, R. N. Dexter, P. M. Bridenbaugh, and B. W. Vea, Phys. Rev. B 16, 4491 (1977).

3. A. Heinrich, W. Cordts, and J. Monecke, Phys. Status Solidi B 107, 319 (1981).

4. J. E. Jaffe and A. Zunger, Phys. Rev. B 27, 5176 (1983).

5. Alex Zunger, Phys. Rev.B 22, 5839 (1980).

6. Alex Zunger and J. E. Jaffe, Phys. Rev. Lett. 51, 662 (1983).

7. S. H. Wei and Alex Zunger, Appl. Phys. Lett. 56, 662 (1990).

8. A. Sileika, Inst. Phys. Conf. Ser. 35, 129 (1977).

9. A. S. Poplavnoi, Y. I. Polygalov, and A. M. Ratner, Izv. Vyssh. Uchebn. Zaved, Fiz. [Sov. Phys. J.] 19, 7 (1976).

10. H. Horinaka, and N. Yamamoto, Oyo Butsuri 60, 112 (1991).

11. V. G. Dmitriev, G. G. Gurzadyan, and D. N. Nikogosyan, Handbook of Nonlinear Optical Crystals, Springer Series in Optical Sciences, Vol. 64, Springer-Verlag Berlin Heidelberg, 1991.

12. R. Poerschke and O. Madelung, Semiconductors - Other than Group IV Elements and III-V Compounds, Data in Science and Technology, Springer-Verlag Berlin Heidelberg, 1992.

13. B. R. Pamplin, Tables of Properties of Semiconductors, CRC Handbook of Chemistry and Physics, Volume 68, pp 102 - 105, 1987-1988.

14. Martin J. Weber, Editor, CRC Handbook of Laser Science and Technology, Vol III, Part 1, CRC Press, Inc., Boca Raton, Florida, 1986.

15. G. D. Boyd, H. Kasper, and J. H. McFee, IEEE J. of Q. Electr. QE-7, 563 (1971).

16. C. K. N. Patel, Phys. Rev. Lett. 16, 613 (1966).

17. J. H. McFee, G. D. Boyd, and P. H. Schmidt, Appl. Phys. Lett. 17, 57 (1970).

18. G. D. Boyd, E. Buehler, and F. G. Storz, Appl. Phys. Lett. 18, 301 (1971).

19. B. F. Levine and C. G. Bethea, Appl. Phys. Lett. 20, 272 (1972). 
20. W. B. Gandrud, G. D. Boyd, J. H. McFee, and F. H. Wehmeier, Appl. Phys. Lett. 16, 59 (1970).

21. R. C. Miller and W. A. Nordland, Phys. Rev. B 2, 4896 (1970).

22. Marvin. J. Weber, Editor, CRC Handbook of Laser Science and Technology, Vol. IV, Part 2, CRC Press, Boca Raton, Florida, 1986.

23. N. M. Ravindra and V. K. Srivastava, Infrared Phys. 19, 605 (1979).

24. Lockheed Sanders-Laser \& Electro-optics, Technical Data Sheet (Zinc Germanium Phosphide), Nov 1, 1993.

25. O. Madelung and M. Schulz, Editors, Landolt-Bornstein: Numerical Data and Functional Relationships in Science and Technology; Group III: Crystal and Solid State Physics: Semiconductors, Volume 22, subvol. a, Springer-Verlag, New York, 1987.

26. N. M. Ravindra and V. K. Srivastava, Infrared Phys. 19, 603 (1979).

27. T. S. Moss, Proc. Phys. Soc. B63, 167 (1950).

28. J. F. Nye, Physical Properties of Crystals, Oxford Science Publications, New York, 1989.

29. J. C. Phillips, Phys. Rev. Lett. 20, 550 (1968).

30. J. A. Van Vechten, Phys. Rev. 182, 891 (1969); Phys. Rev. 187, 1007 (1969).

31. R. A. Soref, J. Appl. Phys. 72, 626 (1992).

32. Robert C. Miller, Appl. Phys. Lett. 5, 17 (1995).

33. C. Flytzanis, in Nonlinear Optics of Organics and Semiconductors, T. Kobayashi editor, Springer Proceedings in Physics, Vol. 36 , Springer-Verlag, Heidelberg, 1989, page 14.

34. Chr. Flytzanis and J. Ducuing, Phys. Rev. 178, 1218 (1969).

35. B. F. Levine, Phys. Rev. B 7, 2600 (1973).

37 Zachary H. Levine and Douglas C. Allan, Phys. Rev. Lett. 66, 41 (1991).

38. Hua Zhong, Zachary H. Levine, Douglas, C. Allan, and John W. Wilkins, Phys. Rev. Lett.. 69, 379 (1992).

36. M. Sheik-Bahae, D. C. Hutchings, D. J. Hagan, and E. W. van Stryland, IEEE J. Quantum 
Electron. 27, 1296 (1991).

39. A. M. Prokhorov and Yu S. Kuz'minov, Ferroelectric Crystals for Laser Radiation Control, Adam Hilger, Bristol, Philadelphia, and New York, 1990.

40. J. L. Shay and J. H. Wernick, Ternary Chalcopyrite Semiconductors: Growth, Electronic Properties, and Applications, Pergamon, New York, 1975.

4 1. S. H. Wei and Alex Zunger, Appl. Phys. Lett. 56, 662 (1990).

42. V. E. Stenger, P. B. Kosel, S. M. Hegde, and M. C. Ohmer, Proceedings of SOTAPOCS XVIII, 93-27, 75, Electrochemical Society, 1993.

43. T. Bell, J. L. Shay, and H. M. Kasper, Phys. Rev. B 9, 5203 (1974).

44. S. I. Radautsan and I. M. Tiginyanu, Jpn. J. Appl. Phys. 32, Suppl 32-3, 5 (1993).

45. U. von Alpen, J. C. Doukhan, B. Escaig, and P. Grosse, Phys. Status Solidi. B 55, 667 (1973).

46. L. S. Dubinskaya, A. D. Galetskaya, and I. I. Farbshtein, Sov. Phys. Solid State 24, 1536 (1983).

47. Joseph J. Loferski, Phys. Rev. 93, 707 (1954).

48. J. Stuke and H. Keller, Phys. Status Solidi 7, 189 (1964).

49. John W. Wilkins, (private communication). 
Table 1. Data used to plot $\chi^{(2)}$ against band gap. Sources of the data are given in the references listed at the bottom of the table. $\delta_{i j}=$ Miller's delta; Index $=$ index of refraction. Units are Gap in $\mathrm{eV}, \chi$ in $\mathrm{pm} / \mathrm{V}, \mathrm{FOM}$ in $(\mathrm{pm} / \mathrm{V}) 2$ and $\delta_{\mathrm{ij}}$ in $\mathrm{m}^{2} / \mathrm{C}$.

\begin{tabular}{llllllll} 
& Compound & Ref No. & Gap & $\chi^{(2)}$ & FOM & Index & $\delta_{\text {ij }}$ \\
\hline 1 & InSb & a,b & 0.23 & 3268.0 & 43322.43 & 3.95 & 0.056 \\
2 & Te & c & 0.33 & 1300.0 & 3834.71 & 4.794 & 0.007 \\
3 & GeSn & a,p,q & 0.36 & 2308.0 & 14614.17 & 4.5 & 0.02 \\
4 & InAs & a,d & 0.36 & 838.0 & 4388.84 & 3.42 & 0.033 \\
5 & CdGeAs2 & c,e,f & 0.57 & 820.0 & 3821.59 & 3.5 & 0.029 \\
6 & GaSb & d & 0.72 & 1256.0 & 7785.99 & 3.7 & 0.028 \\
7 & SiSn & a,p,q & 0.84 & 1010.0 & 4138.01 & 3.95 & 0.02 \\
8 & SiGe & a,p,q & 0.9 & 674.0 & 2224.02 & 3.71 & 0.02 \\
9 & SnC & a,p,q & 1.2 & 556.0 & 1656.46 & 3.6 & 0.02 \\
10 & AgInSe2 & c,e,g,h & 1.2 & 100.0 & 135.87 & 2.6 & 0.031 \\
11 & InSe & a & 1.25 & 200.0 & 131.19 & 4.2 & - \\
12 & InP & d & 1.35 & 287.0 & 505.86 & 3.4 & 0.008 \\
13 & GaAs & b,d & 1.4 & 270.0 & 521.22 & 3.27 & 0.011 \\
14 & CdTe & a,c,i & 1.5 & 336.0 & 1551.50 & 2.63 & 0.077 \\
15 & CuInS2 & c,e,j,k & 1.53 & 19.2 & 5.43 & 2.6 & 0.007 \\
16 & CuGaSe2 & c,e,h,j,k & 1.7 & 70.0 & 60.87 & 2.7 & 0.020 \\
17 & Se & b,c & 1.7 & 159.2 & 344.36 & 2.64 & 0.042 \\
18 & CdGeP2 & c,e,f & 1.72 & 320.0 & 788.62 & 3.2 & 0.025 \\
19 & ZnSiAs2 & c,e,f & 1.74 & 180.0 & 244.89 & 3.2 & 0.016 \\
20 & AgGaSe2 & c,e,g,h,k & 1.8 & 95.0 & 126.90 & 2.6 & 0.030 \\
21 & CdSe & c & 1.8 & 104.0 & 183.87 & 2.5 & 0.047 \\
22 & Ag3SbS3 & c & 1.93 & 28.0 & 9.53 & 2.7 & 0.006 \\
23 & Ag3AsS3 & a & 2 & 50.0 & 31.75 & 2.7 & 0.012
\end{tabular}




\begin{tabular}{|c|c|c|c|c|c|c|c|}
\hline 24 & GaSe & c & 2.021 & 128.0 & 186.59 & 2.8 & 0.029 \\
\hline 25 & $\mathrm{ZnGeP2}$ & $c, e, f$ & 2.05 & 150.0 & 185.21 & 3.1 & 0.020 \\
\hline 26 & $\mathrm{HgS}$ & $\mathrm{b}$ & 2.1 & 100.0 & 142.24 & 2.6 & 0.029 \\
\hline 27 & $\mathrm{GeC}$ & $a, p, q$ & 2.1 & 76.0 & 75.02 & 2.68 & 0.02 \\
\hline 28 & AgAsS2 & $\mathrm{a}$ & 2.14 & 50.0 & 40.00 & 2.5 & 0.022 \\
\hline 29 & b-SiC & $\mathrm{a}, \mathrm{p}, \mathrm{q}$ & 2.26 & 60.0 & 51.80 & 2.59 & 0.005 \\
\hline 30 & $\mathrm{GaP}$ & $\mathrm{c}, \mathrm{d}, \mathrm{m}$ & 2.3 & 200.0 & 335.67 & 3.1 & 0.020 \\
\hline 31 & $\mathrm{ZnTe}$ & $a, c, i$ & 2.3 & 184.4 & 431.89 & 2.7 & 0.043 \\
\hline 32 & $\mathrm{CuGaS} 2$ & $\mathrm{c}, \mathrm{e}, \mathrm{g}$ & 2.43 & 22.0 & 7.93 & 2.5 & 0.011 \\
\hline & & $\mathrm{h}, \mathrm{j}, \mathrm{k}$ & & & & & \\
\hline 33 & $\mathrm{CdS}$ & c & 2.485 & 88.0 & 181.82 & 2.2 & 0.071 \\
\hline 34 & $\mathrm{GaS}$ & $\mathbf{a}$ & 2.5 & 279.0 & 988.68 & 2.7 & - \\
\hline 35 & map & 1 & 2.6 & 12.6 & 11.76 & 1.5 & - \\
\hline 36 & $\mathrm{AgGaS} 2$ & $\mathrm{c}, \mathrm{g}, \mathrm{h}, \mathbf{k}$ & 2.638 & 28.0 & 14.18 & 2.4 & 0.022 \\
\hline 37 & $\mathrm{ZnSe}$ & $\mathrm{c}, \mathrm{m}$ & 2.7 & 156.8 & 444.63 & 2.4 & 0.077 \\
\hline 38 & AgI & c & 2.8 & 20.0 & 5.50 & 2.6 & 0.021 \\
\hline 39 & $\mathrm{CuBr}$ & a & 2.91 & 16.0 & 8.00 & 2.0 & 0.033 \\
\hline 40 & $\mathrm{CuI}$ & a & 2.95 & 16.0 & 5.26 & 2.3 & 0.017 \\
\hline 41 & pom & 1 & 3 & 6.0 & 2.20 & 1.6 & - \\
\hline 42 & $\mathrm{CdGa2S} 4$ & a & 3.05 & 50.0 & 51.37 & 2.3 & 0.030 \\
\hline 43 & $\mathrm{CuCl}$ & a & 3.17 & 14.0 & 7.14 & 1.9 & 0.043 \\
\hline 44 & $\mathrm{ZnO}$ & $a, b, c$ & 3.3 & 3.6 & 0.44 & 2.0 & 0.008 \\
\hline 45 & $\mathrm{ZnS}$ & c & 3.9 & 61.2 & 76.96 & 2.3 & 0.066 \\
\hline 46 & $\mathrm{LiIO} 3$ & $\mathrm{~b}$ & 4 & 11.1 & 2.67 & 2.3 & - \\
\hline 47 & $\mathrm{LiNbO} 3$ & $\mathrm{~b}$ & 4 & 10.9 & 4.40 & 1.9 & 0.004 \\
\hline 48 & urea & 1 & 5.9 & 2.0 & 0.24 & 1.6 & - \\
\hline 49 & $\mathrm{SiC}$ & $\mathrm{n}$ & 6 & 17.2 & 3.93 & 2.7 & - \\
\hline
\end{tabular}




$\begin{array}{llllllll}50 & \text { AlN } & \text { a } & 6.2 & 7.7 & 1.85 & 2.0 & - \\ 51 & \text { BBO } & \text { I } & 6.3 & 1.2 & 0.09 & 1.6 & - \\ 52 & \text { KDP } & \text { o } & 7 & 0.9 & 0.06 & 1.5 & 0.030 \\ 53 & \text { SiO2 } & \text { b } & 8.4 & 0.8 & 0.04 & 1.5 & 0.015\end{array}$

All $\chi^{(2)}$ and Miller $\delta$ data, except IV-IV compounds, are from the CRC Handook on Laser Science and Technology, Vol. III, Ed. Martin J. Weber, CRC Press, Boca Raton, FL, 1986.

a. Editors: O. Madelung and M. Schulz, Landolt-Bornstein: Numerical Data and Functional Relationships in Science and Technology; Group III: Crystal and Solid State Physics: Semiconductors, Volume 22, subvol. a, Springer-Verlag, New York, 1987.

b. R. C. Miller and W. A. Nordland, Phys. Rev. B 2, 4896 (1970).

c. V.G. Dmitriev, G.G. Gurzadyan, and D.N. Nikogosyan, Handbook of Nonlinear Optical Crystals, Springer Series in Optical Sciences, Vol. 64, Springer-Verlag Berlin Heidelberg, 1991. d. Lockheed Sanders-Laser \& Electro-optics, Technical Data Sheet (Zinc Germanium Phosphide), Nov 1, 1993.

e. M. Mondal, K. P. Ghatak, and A. K. Das, Acta Physica Hungarica 65, 43 (1989).

f. H. Hahn and B. Wellmann, Naturwissenschaften 54, 42 (1967).

g. H. Y. Ueng, and H. L. Hwang, Mat. Sci. and Eng. B12, 261 (1992).

h. M. Mondal, S. Banik, and K. P. Ghatak, J. Low Temp. Phys. 74, 423 (1989).

i. N. M. Ravindra and V. K. Srivastava, Infrared Phys. 19, 603 (1979).

j. J. E. Jaffe and A. Zunger, Phys. Rev. B 29, 1882 (1984).

k. J. L. Zyskind and A. Srivastava, J. Crys. Growth 81, 530 (1987).

1. B. R. Pamplin, T. Kiyosawa, and K. Masumoto, Prog. Crystal. Growth Charact. 1, 331 (1979).

m. N. M. Ravindra and V. K. Srivastava, Infrared Phys. 19, 605 (1979). 
n. Elgene R. Nichols, John C. Corbin Jr., Vincent L. Donlan, Technical Report AFAL-TR-74161, pp 61-63, July 1974. Available from NTIS.

o. P. Villars and L. D. Calvert, Pearson's Handbook of Crystallographic Data for Intermetallic Phases; Vols. I, II, III, American Society for Metals, Metals Park, Ohio 44073, 1985 (first printing).

p. R. Soref, Appl. Opt. 31, 4627 (1992).

q. R. Soref, J. Appl. Phys. 72, 626 (1992). 
Table 2. Summary of Numerical Fit Equations for $\chi^{(2)}(\mathrm{pm} / \mathrm{V})$ and for figure of merit $(\mathrm{FOM})(\mathrm{pm} / \mathrm{V}) 2$ for $\mathrm{E}=\mathbf{0 - 8} \mathrm{eV}$ (full gap range), 0-1 $\mathrm{eV}$ (narrow gap range), and $1.8 \mathrm{eV}$ (wide gap range).

Full Gap Range: $\quad \chi^{(2)}=291 \mathrm{E}-1.92$ correlation coef $=0.9$

Narrow Gap Range: $\chi^{(2)}=663 \mathrm{E}^{-.89}$ correlation coef $=.88$

Wide Gap Range: $\quad \chi^{(2)}=510 \mathrm{E}^{-2.6}$ correlation coef. $=0.78$

Full Gap Range: $\quad$ FOM $=666 \mathrm{E}^{-3.0}$ correlation coef. $=0.86$

Narrow Gap Range: $F O M=2324 E^{-1.4}$ correlation coef. $=0.85$

Wide Gap Range: $\quad$ FOM $=1760 \mathrm{E}^{-4.1}$ correlation coef. $=0.76$ 
Table 3. Predicted $\chi^{(2)}(\mathrm{pm} / \mathrm{V})$ and FOM $(\mathrm{pm} / \mathrm{V})^{2}$ values compared with actual values for the three line fits for compounds representative of narrow, mid, and wide energy gap values. $\chi^{(2)}$ :

$\begin{array}{llllll}\text { E } & \text { Full } & \text { Narrow } & \text { Wide } & \text { Actual } & \text { Compound } \\ 0.23 & 4.91 \mathrm{E}+03 & \underline{2.45 \mathrm{E}+03} & 2.26 \mathrm{E}+04 & \underline{3.27 \mathrm{E}+03} & \text { InSb (narrow) } \\ 1.4 & 1.52 \mathrm{E}+02 & 4.91 \mathrm{E}+02 & \underline{2.14 \mathrm{E}+02} & 1.80 \mathrm{E}+02 & \text { GaAs (mid) } \\ 7.0 & 6.88 \mathrm{E}+00 & 1.17 \mathrm{E}+02 & \underline{3.37 \mathrm{E}+00} & \underline{1.00 \mathrm{E}+00} & \text { KDP (wide) }\end{array}$

FOM:

$\begin{array}{llllll}\text { E } & \text { Full } & \text { Narrow } & \text { Wide } & \text { Actual } & \text { Compound } \\ 0.23 & 5.61 \mathrm{E}+04 & \underline{1.84 \mathrm{E}+04} & \mathbf{7 . 6 5 \mathrm { E } + 0 5} & \underline{4.33 \mathrm{E}+04} & \text { InSb (narrow) } \\ 1.4 & 2.41 \mathrm{E}+02 & 1.45 \mathrm{E}+03 & \underline{4.37 \mathrm{E}+02} & \underline{2.32 \mathrm{E}+02} & \text { GaAs (mid) } \\ 7.0 & 1.88 \mathrm{E}+00 & 1.51 \mathrm{E}+02 & \underline{5.63 \mathrm{E}-01} & \underline{1.00 \mathrm{E}-01} & \text { KDP (wide) }\end{array}$


Table 4. Comparison of the calculated and literature values of $\chi^{(2)}$. Calculated values from equations in Table 2.

\begin{tabular}{|c|c|c|c|c|c|c|}
\hline Compound & $\begin{array}{r}\mathbf{E} \\
(\mathbf{e V})\end{array}$ & 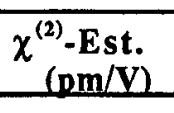 & $\begin{array}{l}\chi^{(2)}-\operatorname{Exp}^{* *} \\
(\mathrm{pm} / \mathbf{V})\end{array}$ & $\begin{array}{r}\text { Rel. } \chi^{(2)} \\
\text { Calculated }\end{array}$ & Exp & $\begin{array}{l}\text { Estimated/ } \\
\text { Exp Value }\end{array}$ \\
\hline$G a \ln P_{2}$ & 1.7 & 130 & - & - & - & - \\
\hline GaAs & 1.4 & 214 & 180 & - & - & 1.19 \\
\hline $\mathrm{AgGaS}_{2}$ & 2.73 & 38.3 & 28 & 1.00 & 1.00 & 1.37 \\
\hline $\mathrm{AgGaSe}_{2}$ & 1.83 & 107 & 95 & 2.79 & 3.39 & 1.13 \\
\hline $\mathrm{AgGaTe}_{2}$ & 1.356 & 233 & $(170)^{*}$ & 6.08 & - & - \\
\hline $\mathrm{HgGa}_{2} \mathrm{~S}_{4}$ & 2.79 & 36.2 & $53.6, \quad 70.4$ & 1.00 & - & $0.56,0.42$ \\
\hline $\mathrm{HgGa}_{2} \mathrm{Se}_{4}$ & 2.1 & 75.3 & - & 2.08 & - & - \\
\hline $\mathrm{Hgln}_{2} \mathrm{Se}_{4}$ & 1.45 & 196 & - & 5.41 & - & - \\
\hline Se & 1.7 & 130 & 159 & 1.00 & 1.00 & 0.82 \\
\hline $\mathrm{Te}_{.286} \mathrm{Se}_{.714}$ & & 510 & $\left(\begin{array}{llll}6 & 2 & 4\end{array}\right)^{*}$ & 3.92 & - & - \\
\hline Te & 0.33 & 1780 & 1300 & 13.69 & 8.18 & 1.37 \\
\hline $\mathrm{ZnGeP}_{2}$ & 2 & 85.4 & 150 & 1.00 & 1.00 & 0.57 \\
\hline $\mathrm{CdGeAs}_{2}$ & 0.57 & 1090 & 820 & 12.76 & 5.47 & 1.33 \\
\hline
\end{tabular}

**Reference 11

*Calculated using ratio, e.g., $233 / 38.3=6.08 ; 28 * 6.08=170$. 
Table 5. Comparison of calculated and literature values for the Figure of Merit. Calculated values from equations in Table 2.

\begin{tabular}{|c|c|c|c|c|c|c|}
\hline Compound & $\begin{array}{l}\mathbf{E} \\
(\mathrm{eV})\end{array}$ & $\begin{array}{c}\text { FOM-Calc } \\
(\mathrm{n} m / \mathrm{V})\end{array}$ & $\begin{array}{l}\text { FOM-Exp } \\
(0 \mathrm{~m} / \mathrm{V}) \underline{2}\end{array}$ & $\begin{array}{c}\text { Relative } \\
\text { Calculated }\end{array}$ & $\begin{array}{l}\text { FOM } \\
\text { Exp. }\end{array}$ & $\begin{array}{c}\text { Estimated/ } \\
\text { Exp Value }\end{array}$ \\
\hline GalnP $_{2}$ & 1.7 & 196 & - & - & & - \\
\hline GaAs & 1.4 & 437 & 232 & - & - & 1.88 \\
\hline $\mathrm{AgGaS}_{2}$ & 2.73 & 27.6 & 23.4 & 1.00 & 1 & 1.18 \\
\hline $\mathrm{AgGaSe}_{2}$ & 1.83 & 144 & 127 & 5.22 & 5.43 & 1.13 \\
\hline $\mathrm{AgGaTe}_{2}$ & 1.356 & 498 & $(422)^{*}$ & 18.04 & - & - \\
\hline $\mathrm{HgGa}_{2} \mathrm{~S}_{4}$ & 2.79 & 25.2 & - & 1.00 & - & - \\
\hline $\mathrm{HgGa}_{2} \mathrm{Se}_{4}$ & 2.1 & 81.7 & - & 3.24 & - & - \\
\hline $\mathrm{Hgln}_{2} \mathrm{Se}_{4}$ & 1.45 & 378 & - & 15.00 & - & - \\
\hline $\mathrm{Se}$ & 1.7 & 196 & 511 & 1.00 & 1 & 0.38 \\
\hline $\mathrm{Te}_{.286} \mathrm{Se} .714$ & 1 & 1760 & $(4589)^{*}$ & 8.98 & - & - \\
\hline Te & 0.33 & 11000 & 10,048 & 56.12 & 19.66 & 1.09 \\
\hline $\mathrm{ZnGeP}_{2}$ & 2 & 99.9 & 185 & 1.00 & 1 & 0.54 \\
\hline $\mathrm{CdGeAs}_{2}$ & 0.57 & 5120 & 3822 & 51.25 & 20.66 & 1.34 \\
\hline
\end{tabular}

*Calculated using ratio 
Table 6. Power-law scaling summary, where $m$ is the bandgap power dependence.

\begin{tabular}{l|lcl}
\multicolumn{2}{c}{$m$} & & \\
\hline FOM & $\chi^{(2)}$ & Bandgap Range (eV) & Reference \\
3.0 & 1.9 & $8-0$ & this work \\
4.1 & 2.6 & $8-1$ & this work \\
1.4 & 0.9 & $1-0$ & this work \\
6 & 3 & $1.4-2.45$ & "nearly" $a b$ initio, refs. 37.38
\end{tabular}


Figure Captions:

Figure 1. Plot of the second order nonlinear coefficient, $\chi^{(2)}$, versus bandgap for a number of chalcopyrites and selected other types of compounds. See Table 1 for specific data. The "nearly" $a b$ initio results (dashed line) and values calculated using Miller's empirical rule, as given by equation 7, are plotted for comparison. open boxes: narrow gap; open circles: wide gap; x: Miller's rule; filled diamonds: $a b$ initio calculated values; the solid lines are fits for each range; the dotted line is the fit for $a b$ initio values.

Figure 2. Plot of the figure of merit (FOM) versus bandgap for a number of chalcopyrites and selected other types of compounds. The "nearly" ab initio result (dashed line) is shown for comparison. Open boxes: narrow gap; open circles: wide gap; filled diamonds: ab initio values; solid lines: fits for two ranges; dotted line: fit for $a b$ initio values. 


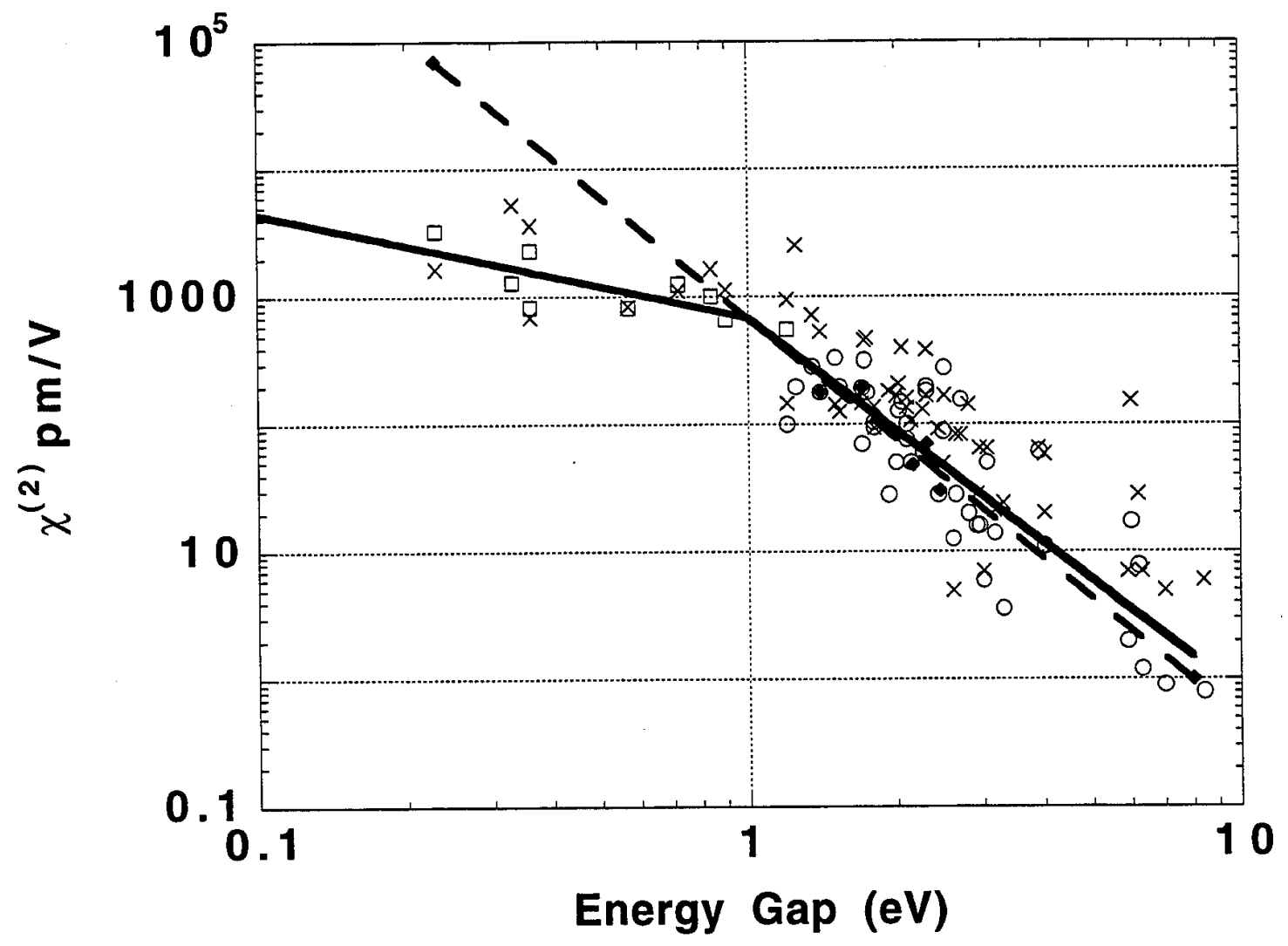




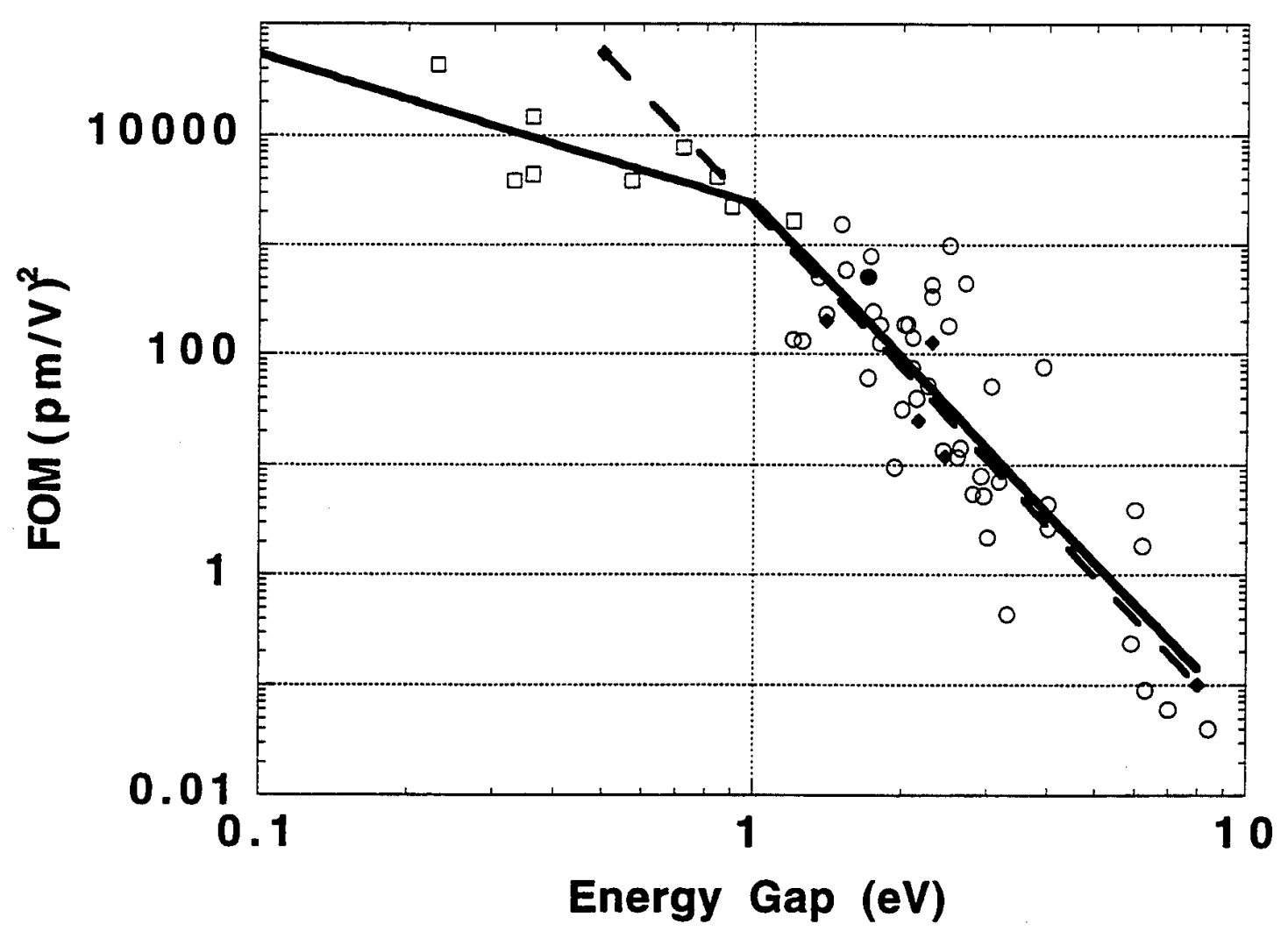

